\title{
Information Demand Context Modelling for Improved Information Flow: Experiences and Practices
}

\author{
Magnus Lundqvist ${ }^{1}$, Eva Holmquist ${ }^{2}$, Kurt Sandkuhl ${ }^{1}$, \\ Ulf Seigerroth $^{1}$, and Jan Strandesjö ${ }^{3}$ \\ ${ }^{1}$ School of Engineering at Jönköping University, \\ P.O. Box 1026, 55111 Jönköping, Sweden \\ \{Magnu. . Lundqvist, Kurt.Sandkuhl\}@jth.hj.se \\ Ulf.Seigerroth@ihh.hj.se \\ ${ }^{2}$ SYSteam Management AB, Box 439, 56125 Huskvarna, Sweden \\ Eva.Holmquistasysteam.se \\ ${ }^{3}$ Proton Finishing, Box 1002, 33129 Värnamo, Sweden \\ Jan.Strandesjo@proton.se
}

\begin{abstract}
The paper addresses the field of modelling information demand context, which can be considered as an application of enterprise modelling techniques with focus on capturing information demands. Based on industrial cases from automotive industries, experiences and practices of information demand modelling are presented and investigated. This includes the specific perspective taken in the method for information demand analysis, common challenges experienced in demand modelling, the validity of practices from participative enterprise modelling for context modelling and practices of context modelling.
\end{abstract}

Keywords: Enterprise Modelling, Information Demand, Information Logistics, Context Modelling, Information Demand Context.

\section{Introduction}

Since more than 20 years, one of the traditional application purposes of enterprise modelling has been to understand the current situation in an enterprise under consideration, in order to be able to propose improvements [1]. Various approaches and methods dedicated for this purpose were developed in areas such as business process reengineering [2], process improvement [3], process innovation or organisational renewal [4]. This significant body of knowledge is the basis for the work presented in this paper.

Another field of relevance is the area of information logistics [5]. Information logistics addresses the challenge of improving information flow in organisations. Recent studies showed that information overload is increasingly perceived as a problem even on an enterprise level [6] calling for innovative approaches to overcome this challenge.

In order to improve information flow in organisations, the development of context models has been found useful [7]. Context models - to be more precise information demand context models - can be considered as application of enterprise modelling 
techniques for capturing selected parts of an enterprise using a representation and modelling method tailored for the purpose of capturing information demand.

This paper summarise the background, presents an industrial case for information demand modelling and includes examples of the use of information demand contexts based on that case. Finally it discusses practices and experiences from context modelling in comparison to enterprise modelling practices.

\section{The Constituent of Information Demand}

Information demand as a concept is based upon empirical work performed by the Centre for Evolving IT in Networked Organisations during the period 2005-2007. The results from this work resulted in a number of verified conjectures regarding the nature of information demand as well as a deeper understanding of how information is used with regards to work-related tasks [8]. These results have been used as the foundation on which the method discussed in Section 4. has been developed. The definition of information demand used throughout the paper is:

Information demand is the constantly changing need for relevant, current, accurate, reliable, and integrated information to support (business) activities, when ever and where ever it is needed.

While this definition gives an initial conceptual view on information demand it is not sufficient as a basis for method development. Consequently, additional analysis and conceptualisation was performed to identify different dimensions of information demand. It was concluded [8] that contextual aspects such as role, tasks and resources define information demand while it is affected by situational and individual aspect such as competence, time, location and social networks etc. Since the contextual aspects are considered most important [7], focus in this paper will be on parts in the developed method that are relevant for modelling information demand contexts.

Information demand as it is defined and referred to here, has a strong relation to the context in which such a demand exists. In order to know something about information demand, something need to be known about the organisational role having the demand and for what task the information is demanded as well as the setting in which such tasks are performed. Thus, the concept of information demand context has been defined both conceptually and as the core of the method with respect to modelling, evaluating and analysing of information demand. The definition of information demand context that has been used during the method development is the following:

An Information Demand Context is the formalised representation of information about the setting in which information demands exist and comprises the organisational role of the party having the demand, work tasks related, and any resources and informal information exchange channels available, to that role.

This definition and the empirical data that supports it, conclude that information demand not only is connected to a role, and therefore also always is considered to be role-based, but also to additional enterprise related aspects as illustrated in Figure 1. below. The informal aspects of information demand mentioned in the definition above can, although not covered in this paper, also be a part of the context by considering social networks as resources. 


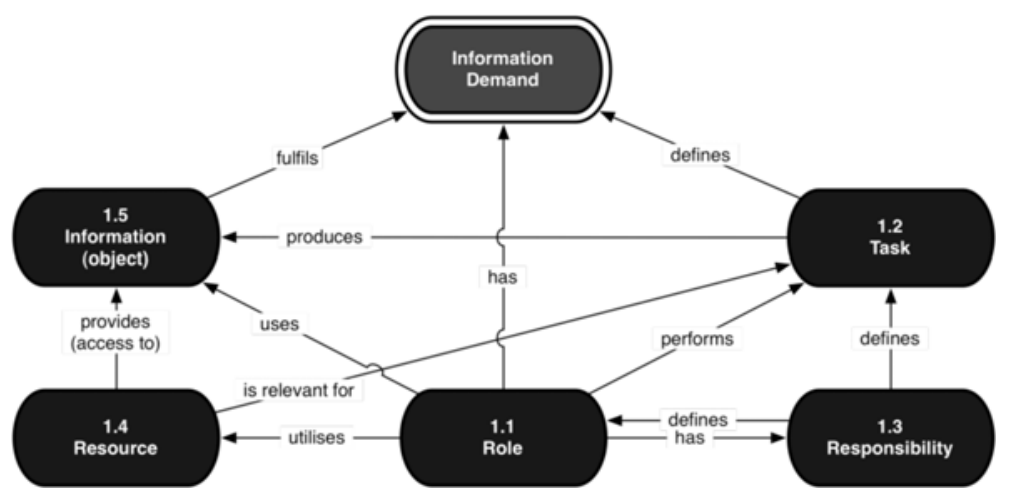

Fig. 1. Context-related concepts with respect to information demand

This view on information demand context allows traditional enterprise modelling techniques to be used, with a somewhat different focus, in order to reach an initial understanding of role-based information demand. In Section 4. a number of practical experiences from an industrial case and the implication it has for the development of a method component for analysing information demand will be described in more detail.

\section{Industrial Application Cases}

Within InfoFLOW, modelling of information demand context was performed in a number of industrial cases in order to collect experiences from various situations and domains in order to iteratively develop and improve the modelling approach. This paper will briefly discuss just one industrial case in order to expose typical modelling purpose, the process of modelling, the organisation frame, and results.

The industrial case defining the context for work presented in this paper is taken from manufacturing industries and focuses on engineering change management within one of the industrial partners. Proton Finishing (henceforth Proton) is a sub-supplier to different first-tier suppliers in automotive and telecommunication industries and performs various surface treatment services of metal components. Surface treatment in this context includes different technical or decorative coatings to achieve certain functionality or appearance.

In the Proton case four major activities were conducted in accordance with the list below. These activities have had a framing focus of dealing with change management in the finishing production process where Proton is a subcontractor to an OEM in the automotive industry. The challenge for Proton is to handle the continuously incoming changed specifications for the products that they are producing for the OEM. The major activities in this project was therefore:

1. General modelling of how Proton was handling change management in the production processes. The major result from this activity was descriptions of Proton's processes and a number of described change areas.

2. Validation of process descriptions, prioritisation of change areas, and planning of how to proceed. 
3. Detailed process modelling and refinement of improvement areas at Proton.

4. Information demand analysis of a specific part of Proton's sales process (from quotation to production planning).

In this paper focus is on the fourth session in the list above since it has served as the major basis for development of a method component for information demand context modelling and analysis. While there usually are a number of scoping activities preceding the context modelling, such activities were not needed here as the scope was defined in activity 1, 2, and 3 in the list above. The fourth session, the actual modelling, was divided into two main activities, 1) interviews, and 2) an information demand modelling seminar. During these two activities the following persons were involved, two researcher from Jönköping University, one consultant from SYSteam and four persons from Proton (head of quality, sales representative, technical support/technical in-house sales, and production planner).

The interviews were performed in a semi-structured manner during two hours where one researcher was guiding the interview and the other researcher together with the consultant took notes. The interview was also recorded as basis for later analysis and further development of the information demand analysis method. The main purpose with the interviews was to set the stage and decide the focus for the next activity; a seminar under which an initial version of the information demand analysis method (a method hypothesis) was tested.

After the interviews and a short planning meeting the information demand modelling seminar was performed. During this modelling seminar one researcher acted as modelling facilitator to move the modelling activities forward. The major purpose of the modelling seminar was to describe the information demand for different roles based on their assignments in the sales process. The modelling seminar was performed in a participative way where the representatives from Proton were actively involved in the modelling. The modelling was performed on plastic sheets with sticky notes and whiteboard markers. The remaining researcher and the consultant participated during the modelling seminar by observing, documenting and asking questions regarding clarification of aspects of the domain that was in focus. The result from the modelling seminar was the empirical foundation to a method component for information demand context modelling, specifying a number of procedures, a notation and a number of concepts on which to focus. The result from the seminar has also been used by the head of quality at Proton to elucidate and share knowledge amongst the employees about certain dimensions in the change management process. The models have served as an instrument to develop shared knowledge amongst roles at Proton about different aspects of the practice in terms of information demand and information flow.

\section{Practices of Information Demand Modelling}

In this section information demand and information context modelling as concepts are discussed in the light of the implications from the industrial case covered in Section 3. with respect to common problems and methodological support. 


\subsection{Common Problems Related to Information Demand}

Most organisations have problems related to information demand in some way or another and many of them are also quite common independently of organisation or domain. However, the effects of most of these problems can also be reduced relatively simply by visualising the information demand of the organisation. In this section some of those problems will be describe and exemplified, partly based on experiences from the industrial case covered in Section 3. but also grounded in SYSteam's many years of system analysis experience within industrial contexts. Similar problems are known from the area of data quality.

\subsubsection{Superfluous Information}

A very common problem in the industry is the constant stream of information being supplied to roles despite there being no need for it. Often the reason behind this is that the information once was needed, but the information demand changed over time. This results in unnecessary work having to be performed, work that in the current market no longer can be afforded.

One example of this is the administrator which every month spends a couple of days computing statistics for the sales department. These statistics were used to plan the sales department work for the next month, but nowadays reports from an ERPsystem are used instead. The administrator is however not aware that the information is no longer needed.

Another example is the construction department, which produces a lot of drawings and specifications to be used by the production department. They are not certain that all these documents are needed anymore, but they do not dare stop producing them if someone actually does need them.

\subsubsection{Gap in the Information Flow}

Another very common problem is that there often is a gap in the information flow. The information is supplied, but the roles needing the information are not receiving it. One reason can be that the roles supplying the information are not aware of all roles that need the produced information and therefore do not distribute it accordingly. Another reason can be that the roles in demand of the information do not know where the information is available or how it is distributed. A third reason is that the information is supplied through a gateway role, i.e. the only purpose for this role to get the information is to supply it to any role needing it. A final reason might be lack in technical support; information is simply not stored in a system or location that supports the proper distribution of it.

One example of this is customer relationship related information. The production department has all information regarding any problems the customers have had with the delivery of their products, but this information does not reach the sales department sometimes resulting in awkward situations with customers and possible loss of sales as a consequence.

Another example is the specification of the raw material in an ERP-system needed by the purchase department and the production planners. The relevant information is gathered by the warehouse personnel upon arrival and then handed to the machine operators to input it into the ERP-system. As the operators have no 
need for this information on their own, this task is always down prioritized and consequently raw material is always specified too late.

\subsubsection{Information Gathered at the Wrong Time}

It is also very common that information is gathered at the wrong time. The reason for this often is that roles, which easily can gather information at the correct time, are not aware that they should.

One example of this is customer invoice information. It is practical to, when the sale is made, gather the information about where to send the invoice. Most sales department however, does not do this because they are not thinking about invoicing as one of their activities and are therefore not aware of what information is needed. This results in the roles performing the invoicing trying to find this information when the invoice should be sent. At that time it is much harder to get the information.

\subsubsection{Outdated and/or Incorrect Information}

Another common problem is the use of outdated and/or incorrect information. This is often due to that individuals do not use the correct source of information. They can be asking another person who they think has the most recent information or information stored elsewhere.

One very common example of this is the use of outdated contract templates. The correct templates are often stored on the intranet but people tend to use the latest contract they wrote as a template resulting in faulty contracts.

\subsection{Information Demand Modelling}

Based on the industrial case and the typical problems described above, various approaches to modelling information demand have been used. The result is a suggestion on a highly flexible component-based method defining a framework for analysing information demand guided by a set of important principles through the application of a number of method components and a unified representation. In this paper focus is on the method component for modelling and analysing information demand contexts, as this is the core of the method.

From a principle point-of-view, modelling information demand relies heavily on stakeholder participations. While it certainly would be possible to base the analysis on existing enterprise descriptions this would not ensure the strong connection to roles required. Therefore it is considered of crucial importance that the modelling is performed in cooperation with the actual individuals having the roles to be modelled. Furthermore, as supported by the underlying, and empirically supported, theory, information demand is always role-based. Consequently, the investigative focus of information demand modelling should not be process-based since this would take focus from many of the relevant aspects of information demand.

\subsubsection{A Method for Information Demand Modelling and Analysis}

Identifying, modelling and analysing information demand is, based on the empirical background, considered as a prerequisite to building various technical solutions for providing demand-driven information supply. As mentioned in Section 2. understanding information demand requires understanding of information demand contexts 
in addition to a number of aspects. In Figure 2. below an overview of a framework for achieving such understanding is presented. Since context is considered central to information demand analysis, methodological support for modelling such contexts is at the core of the framework. However, in order to be able to perform any meaningful context modelling a clear scope is needed. Consequently, the process starts with scoping activities. Also, depending on the requirements and needs relevant for the specific case additional aspects of information demand might be analysed and modelled.

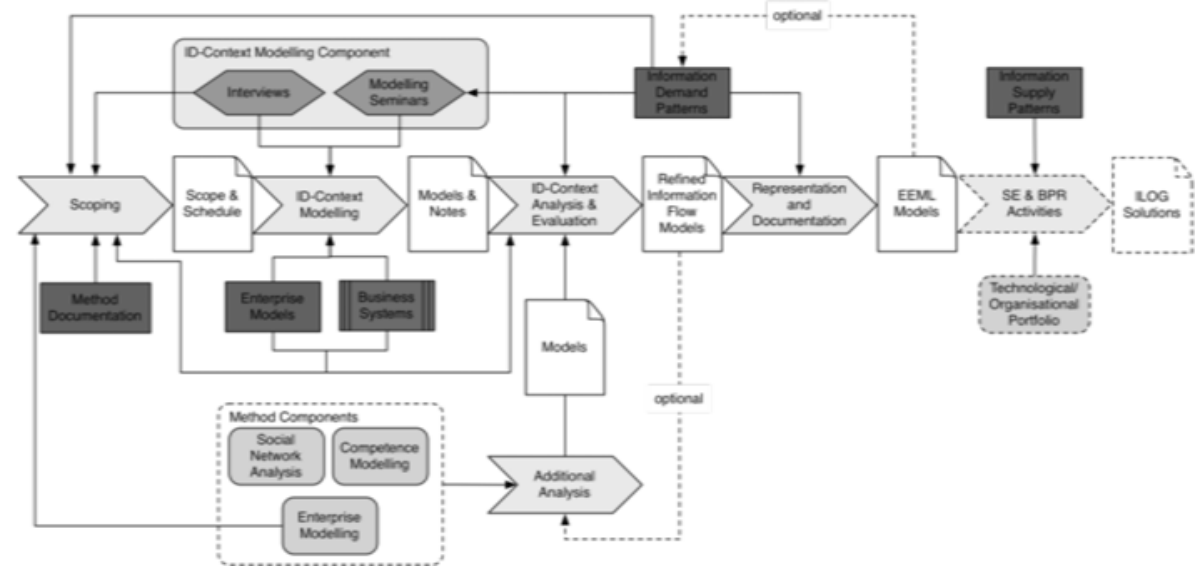

Fig. 2. An overview of the process of analysing information demand

In order for any context modelling and analysis to be possible a clear scope is considered as a prerequisite. Scoping is the process of defining the area of analysis and is done with the purpose of selecting the part of an organisation to analyze with respect to information demand as well as identifying the individuals that will be providing the necessary information during the continued analysis activities. Scoping also serves the purpose of facilitating the understanding and identification of the analysed party's perceived problems motivating them to engage in information demand analysis. Furthermore, it also facilitate the identification of intensions, goals and expectation such parties might have with doing so.

Supporting the method user in the various scoping activities there are a number of different tools, techniques and information. Using traditional enterprise techniques as process modelling, goal modelling and concept graphs can facilitate a shared understanding between all involved parties and thereby ensuring minimising of time and effort needed for continued activities. As the scoping was an integrated part of the case described in Section 3. and aspects of information demand modelling such as competence modelling, documentation and representation etc. are outside the scope of this paper, the rest of this section will focus mainly on the context modelling and analysis parts of the method in relation to the industrial case.

\section{Information Demand Context Modelling}

Due to the nature of information demand the next step of the process after scoping, is to identify and capture contexts. Doing so rely heavily on participative activities such 
as joint modelling seminaries where the informants themselves construct models and the method user facilitates the process by supporting and helping the informants. As illustrated in Figure 1. the conceptual focus is rather small during this phase of the process and furthermore, the focus is solely on information demand within the defined scope. No regards are given to the sequence of activities and resource availability etc. The key to context modelling is instead to identify the interrelationship between roles, tasks, resources and information.

The format and appearance of the actual models produced during these seminars is not important as long as the models capture the information relevant for the continued process. Rather, the choice of techniques used has to be dependent on the situation and the requirements following from it. However, Figure 3. below introduce a notation that can be used for this purpose by giving an example taken from the academic world (the reason behind using this example rather than the models resulting from the industrial case is due to confidentiality regarding Proton Finishing's business processes).

\section{Information Demand Context Analysis and Evaluation}

Once the necessary knowledge about information demand contexts within the scope is gained it can be used for a number of different purposes. From Figure 3. a number of constructs relating to problems identified in Section 4.1. can be identified. The notation allows for representing superfluous information (relating to 4.1.1.) as exemplified by the information object "Registration Status" supplied to the role Examiner. The same is true for gaps between information demand and information actually supplied (relating to 4.1.2.) exemplified by amongst others "Course Evaluation" in Figure 3. Furthermore, the problems relating to dated information (4.1.4), can be partially dealt with by applying temporal conditions to information demand as is done with the task "Sign up for Exam" for the role "Course Participant". Such temporal attributes can also be connected directly to information objects and not only to the tasks motivating the demand for information as in this example.

Visualising information demand and flow in this manner also helps with reducing the effects of problems relating to information gathered at the wrong time (4.1.3.) as the visualisation in itself facilitates the understanding of the information demand in a wider organisational perspective. There is also an inherent value in grouping information by role independently of processes as this gives an overview of each roles general situation with respect to information flow.

During this phase of the process it also suitable to evaluate the results with respect to motivation and purposes expressed during the scoping activities. Focusing on information demand contexts only provide an initial view of information demand without any consideration given to such aspects as individual competence, organisational expectations and requirements in terms of goals, processes etc. Depending on the intentions behind performing the analysis further activities might be required. The method provides a number of method components supporting such activities. Since the main focus of the method presented here is on information demand it utilises existing procedures and notations for such additional aspects rather than defining new ones. Consequently, if the method user wishes to investigate such additional aspects of information demand, he or she can do this by using subsets of the following methods, notations and languages: 


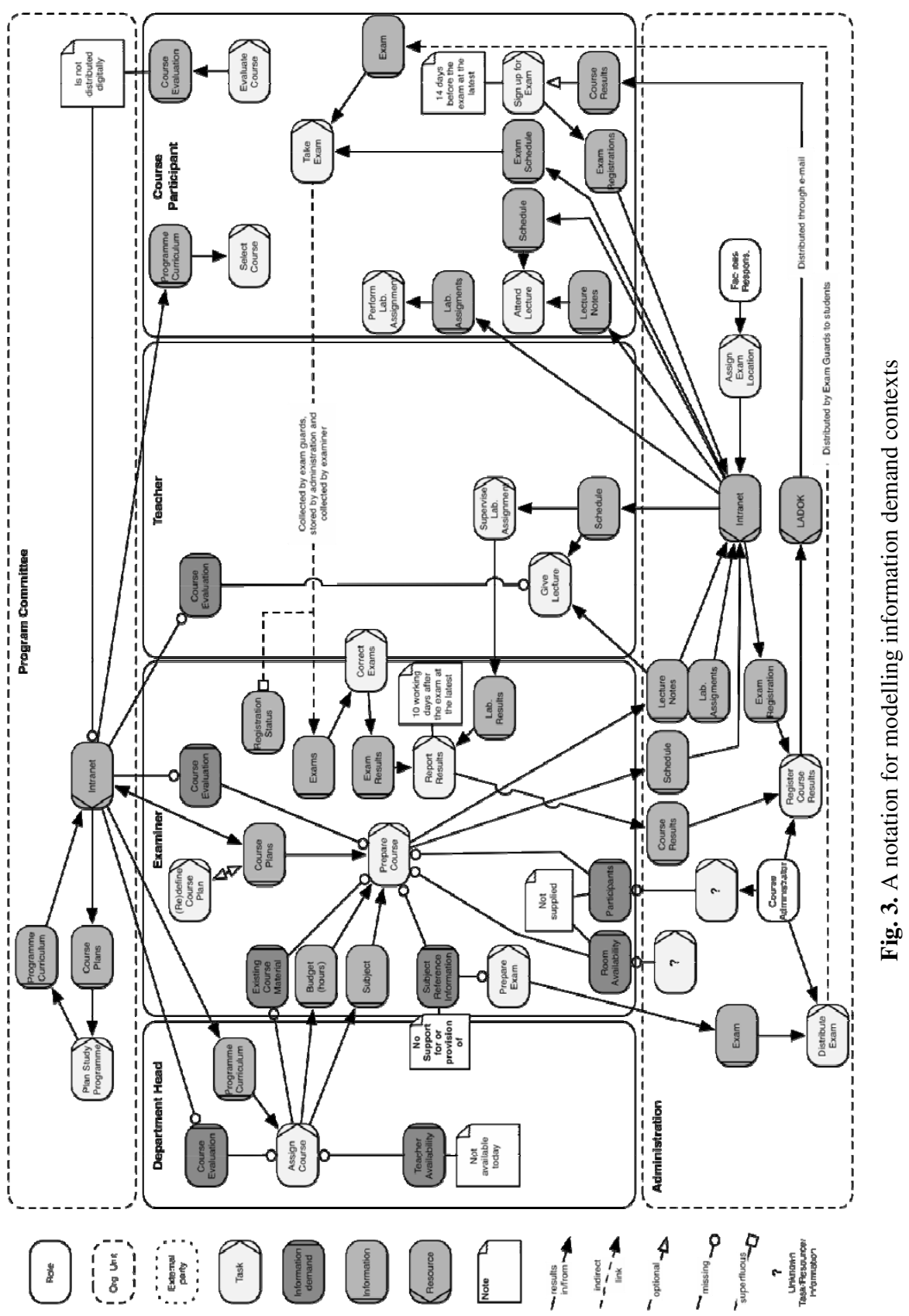


- Enterprise Knowledge Development (EKD) - a method for generating knowledge about organisational functioning and reasons for change by analysing traditional enterprise aspects in a participative manner with support of a number of description techniques and guidelines.

- I-star (i*) - a method for modelling social networks in terms of the concepts typically found within the area of enterprise modelling.

- Unified Enterprise Competence Modelling Language (UECML) - an extension to the Unified Enterprise Modelling Language focusing on modelling competence with respect to mainly roles and activities.

Whilst no further details on utilising these methods, notations and languages are given in this paper the results from doing so always have to be evaluated with respect to the contexts identified during the previous phase. The reasoning behind this is simply that the method presented here is not a method for analysing traditional enterprise aspects. Its only goal is to identify and understand the information demand within an organisation. Everything that is done as part of the analysis efforts should therefore also be focused on the role-based nature of information demand. Doing so requires one to relate any knowledge gained to the information demand contexts. That is to say, such additional aspects are only relevant in the sense that they influence the initial view on information demand generated by the context modelling and analysis. Examples of this might be individual competence that differentiates between the information needed by two separate individuals having the same role and performing the same tasks within an organisation. Consequently, this phase of the process has to be iterated over for every additional analysis activity that is performed to ensure that the strong connection to the contexts is kept.

\section{Reflections and Discussion}

\subsection{Methods Supporting Action}

There are several things that influence, guide and inspire us, when performing qualified investigations, modelling and analysis. The sources of guidance and influence can be more or less explicit. They can be of a tacit nature in terms of different experiences that we have and that we are recalling in the actual work situation. They can also be explicitly formulated in different method descriptions that we follow. Somewhere between experiences and methods we also have theories that directs us without giving such explicit prescriptive directives as methods. In addition to this we can also use computerised tools in which the method has been implemented. The use of methods, theories and tools can therefore be regarded as action knowledge that we can agree with and seek support from during information demand analysis, i.e. methods, theories, and tools are examples of supporting instruments that we can use when we are performing information demand analysis. This conceptualisation of support for actions is also described in Figure 4. 


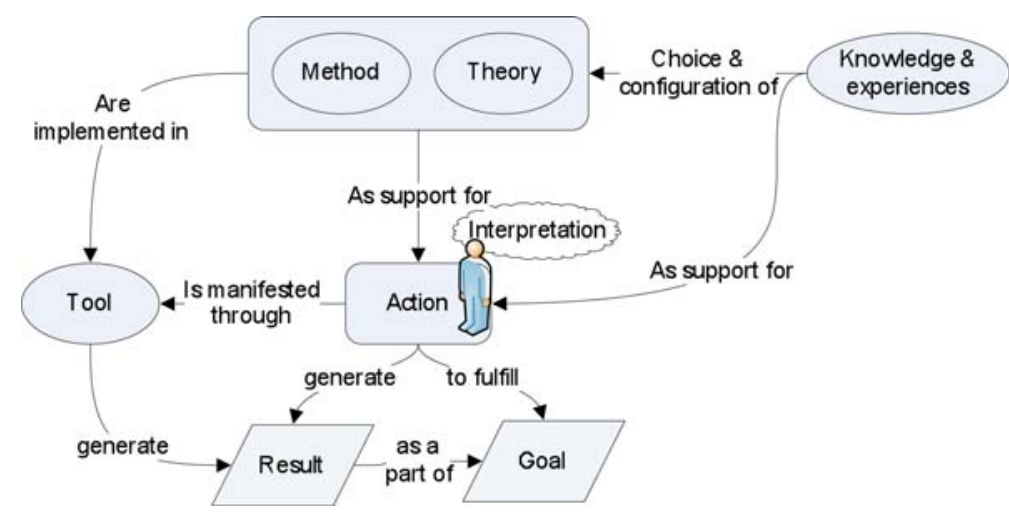

Fig. 4. Support for information demand analysis

The main reason for this elaboration on different types of support for actions is to structure, formalise and clarify different types of support that are used during information demand analysis. In this paper we have put a method as support for information demand analysis in focus and therefore we also need to present a conceptualisation that describes method as a phenomenon.

A method is prescriptive in character since it gives us guidance on what to do in different situations in order to reach certain goals. During modelling there is usually a need to document different aspects and many methods therefore include roles for representation, which often is called modelling techniques or notations. Such methods also provide procedural guidelines, which many times are tightly coupled to notation. The procedure involves some meta-concepts as process, activity, information, and object, which are parts of the prescribed procedure. They are also parts of the semantics of the notation. The concepts are the cement and the overlapping parts between procedure and notation. Methods can thus be crystallised into:

\section{Perform action $A$, in order to reach goal $G$}

It has now been stated that procedure, notation and concepts, amongst other things, constitute methods. When there is a close link between procedure, notation, and concepts, it is referred to as a method component [9]. The concept of method component is similar to the concept Method Chunk [10] and [11] and the notion of method fragment [12]. A method is often a compound of several method components to what many times is called a methodology [13]. These different method components together form a structure called a framework, which includes the phase structure of the method.

All methods build on some implicit (tacit) or explicit perspective. Such a perspective includes values, principles and categories (with definitions), which are more fully expressed in the method and its method components. The perspective is the conceptual and value basis of the method and its rationality.

An additional aspect of methods is labelled co-operation principle; i.e. how different persons interact and co-operate when performing method guided work. Cooperation principles have to do with roles and division of work in the process. This aspect is labelled collection principles and it is conceptually important to distinguish 
between a procedure ("what question to ask"), a co-operation principle ("whom is asking the question") and a collection principle ("how is the answer collected"). A method component (with procedures) can be used within several different cooperation and collection principles, as e.g. seminars, brainstorm sessions, interviews and questionnaires. The central parts of this method theory are illustrated in Figure 5. below [14] [15] [9]. This notion of methods is the conceptual base that we have used for structuring the method for information demand analysis.

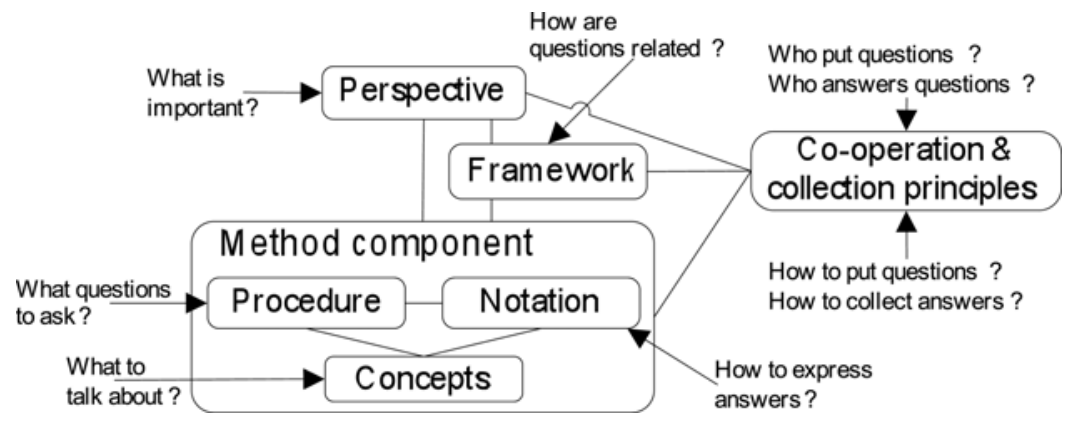

Fig. 5. The notion of method

\subsection{Validity of Practices from EM}

Context modelling in the industrial cases presented in Section 3. was conducted in a participative manner, as the researchers involved had experience in this way of working, considered it as best practice for the problem at hand and it created a shared understanding of the current situation [16]. Information demand context modelling is similar to enterprise modelling, but still a different approach due to the different perspective taken. Thus, it should be examined whether proven experiences and recommendations for participative modelling can be transferred to context modelling. This section will present the lessons learned in this area by discussing how and to what extent the recommendations for participative modelling proposed by Stirna et al [17] were used in the context modelling cases.

Table 1. shows the recommendations published in Stirna et al [17] and compares them to the experiences from the context modelling cases. The recommendations were divided into five groups, which are reflected in the table. When describing the experiences, we will use

- "confirmed", if the practice was applied in the cases and usefulness for context modelling was confirmed,

- "not applied", if the practice was not applied, i.e. no statement can be made regarding validity for context modelling

- "not confirmed", if the number of cases was too small in order to confirm the validity. However, this does not necessarily mean that the practice is not valid.

- "modified", if the practice was enhanced or changed. 
Table 1. Comparison of recommendations and experiences

\begin{tabular}{|c|c|}
\hline $\begin{array}{l}\text { Recommendation from Stirna et al } \\
(2007)\end{array}$ & Experiences from Context Modelling \\
\hline \multicolumn{2}{|l|}{ 1. Assess the organisational context } \\
\hline $\begin{array}{l}\text { understanding the organisation's } \\
\text { power and decision-making structure } \\
\text { is essential }\end{array}$ & $\begin{array}{l}\text { Confirmed, but in only one of the cases, since } \\
\text { the other three cases were part of the already } \\
\text { established InfoFLOW project. }\end{array}$ \\
\hline $\begin{array}{l}\text { Organisational culture has significant } \\
\text { impact }\end{array}$ & $\begin{array}{l}\text { Not confirmed. The culture in the cases was } \\
\text { quite similar, i.e. there was an insufficient } \\
\text { basis to confirm the practice }\end{array}$ \\
\hline $\begin{array}{l}\text { Interviews with stakeholders before } \\
\text { starting the project may reveal hidden } \\
\text { agendas }\end{array}$ & $\begin{array}{l}\text { Confirmed. Not all participants were } \\
\text { interviewed before the modelling sessions, } \\
\text { but most of them, which proved to be a good } \\
\text { preparation }\end{array}$ \\
\hline \multicolumn{2}{|l|}{ 2. Assess the problem at hand } \\
\hline $\begin{array}{l}\text { Interview key decision maker or } \\
\text { conduct participative EM sessions for } \\
\text { understanding the actual problem }\end{array}$ & $\begin{array}{l}\text { Confirmed. Both ways were used (interviews } \\
\text { and sessions) }\end{array}$ \\
\hline $\begin{array}{l}\text { Understand the complexity of the } \\
\text { project (fairly simple, complex or } \\
\text { wicked }\end{array}$ & $\begin{array}{l}\text { Not confirmed. Too few cases were } \\
\text { considered; none of them can be categorised } \\
\text { as wicked problem. }\end{array}$ \\
\hline \multicolumn{2}{|l|}{ 3. Assign roles in the modelling process } \\
\hline Modelling facilitator & $\begin{array}{l}\text { Confirmed. This role is considered as } \\
\text { essential. }\end{array}$ \\
\hline Tool operator & $\begin{array}{l}\text { Modified: the tool was used after the session. } \\
\text { The tool operator was rather an assisting } \\
\text { facilitator. }\end{array}$ \\
\hline Modelling participant / domain expert & Confirmed. \\
\hline $\begin{array}{l}\text { 4. Acquire resources for the project in } \\
\text { general and for preparation efforts in par- } \\
\text { ticular }\end{array}$ & $\begin{array}{l}\text { Not applicable in } 3 \text { of the cases as they were } \\
\text { part of the InfoFLOW project. Confirmed in } \\
\text { one case. }\end{array}$ \\
\hline \multicolumn{2}{|l|}{ 5. Conduct modelling sessions } \\
\hline clear objectives of practical value & $\begin{array}{l}\text { Confirmed. The objectives were always } \\
\text { related to information demand and } \\
\text { information flow issues. }\end{array}$ \\
\hline $\begin{array}{l}\text { modelling notation that everyone } \\
\text { understands }\end{array}$ & $\begin{array}{l}\text { Confirmed. Notation was introduced very } \\
\text { thoroughly. }\end{array}$ \\
\hline $\begin{array}{l}\text { Do not "train" the modelling partici- } \\
\text { pants in method knowledge }\end{array}$ & $\begin{array}{l}\text { Confirmed. This would not contribute to } \\
\text { context modelling. }\end{array}$ \\
\hline Keep everyone involved and focused & $\begin{array}{l}\text { Confirmed. This is essential for success of } \\
\text { the sessions. }\end{array}$ \\
\hline Do not accept unknown participants & $\begin{array}{l}\text { Not applied, i.e. there were no "intruders" to } \\
\text { be taken care of. }\end{array}$ \\
\hline $\begin{array}{l}\text { problem owner should not dominate } \\
\text { the seminar }\end{array}$ & $\begin{array}{l}\text { Not confirmed. There always were several } \\
\text { problem owners, i.e. dominance of only a few } \\
\text { participants was not an issue. }\end{array}$ \\
\hline Establish a common vocabulary & Confirmed. \\
\hline Develop models in parallel & $\begin{array}{l}\text { Not applied. Models were developed after the } \\
\text { sessions. }\end{array}$ \\
\hline
\end{tabular}


Table 1. (Continued)

\begin{tabular}{|l|l|l|}
\hline $\begin{array}{l}\text { Make concrete decisions in the } \\
\text { session }\end{array}$ & $\begin{array}{l}\text { Confirmed regarding decisions about first } \\
\text { changes in information flow and regarding } \\
\text { next steps to take }\end{array}$ \\
\hline Model should deliver a solution & $\begin{array}{l}\text { Not applied. Model aimed at creating a joint } \\
\text { understanding. }\end{array}$ \\
\hline $\begin{array}{l}\text { Make sure that everyone knows what } \\
\text { will happen after the seminar }\end{array}$ & Confirmed. \\
\hline
\end{tabular}

The overall impression is - not surprisingly - that an overwhelming part of the recommendations for participative modelling were found useful and accurate for context modelling. However, the number of cases this result is based on was rather small. Furthermore, there is the danger of a certain bias regarding utility of the original recommendations, due to tight working relationships of the authors.

\section{Summary and Future Work}

The paper presented practices and experiences from information demand context modelling based on several industrial cases. The modelling approach used is a newly developed method for this purpose, which takes a role-centric view and focuses on capturing the role's tasks and responsibilities and the information required for these tasks and responsibilities. The method consists of several method components, which to a substantial part are grounded in enterprise modelling traditions.

Based on industrial cases from automotive industries, experiences and practices of information demand modelling are presented and investigated. This includes the specific perspective taken in the method for information demand analysis, common challenges experienced in demand modelling, the validity of practices from participative enterprise modelling for context modelling and practices of context modelling.

\section{Acknowledgements}

Some parts of the research presented were financed by the Swedish Knowledge Foundation (KK-Stiftelsen) through grant 2005/0252, project "Information Logistics for SME (InfoFLOW)".

\section{References}

1. Harmon, P.: The Scope and Evolution of Business Process Management. In: vom Brocke, J., Rosemann, M. (eds.) Handbook on Business Process Management. Springer, Heidelberg (2009)

2. Davenport, T.H.: Process Innovation. Reengineering Work Through Information Technology. Harvard Business School Press, Boston (1993) 
3. Humphrey, W.S.: Software Process The improvement - A Personal View: How it Started and Where it is Going. Software Process The Improvement and Practice 12, 223-227 (2007)

4. Warner, B.W.: Organisational Development - A Process of Learning and Changing. Addison Wesley, Reading (1994)

5. Deiters, W., Löffeler, T., Pfenningschmidt, S.: The Information Logistical Approach Toward a User Demand-driven Information Supply. In: Spinellis, D. (ed.) Cross-Media Service Delivery, pp. 37-48. Kluwer Academic Publisher, Dordrecht (2003)

6. Öhgren, A., Sandkuhl, K.: Information Overload in Industrial Enterprises - Results of an Empirical Investigation. In: Proceedings ECIME 2008, London, UK (2008)

7. Lundqvist, M.: Context as a Key Concept in Information Demand Analysis. In: Proceedings of the Doctoral Consortium associated with the 5th Intl. and Interdisciplinary Conference on Modelling and Using Context (Context 2005), Paris, France, pp. 63-73 (2005)

8. Lundqvist, M.: Information Demand and Use: Improving Information Flow within Smallscale Business Contexts. Linköping studies in science and technology, Linköping University, Department of Computer and Information Science, Linköping, Sweden (2007)

9. Röstlinger, A., Goldkuhl, G.: På väg mot en komponentbaserad metodsyn (in Swedish). Presented at VITS Höstseminarium 1994, Linköping University, Linköping, Sweden (1994)

10. Ralyté, J., Backlund, P., Kühn, H., Jeusfeld, M.A.: Method Chunks for Interoperability. In: Embley, D.W., Olivé, A., Ram, S. (eds.) ER 2006. LNCS, vol. 4215, pp. 339-353. Springer, Heidelberg (2006)

11. Mirbel, I., Ralyté, J.: Situational method engineering: combining assembly-based and roadmap-driven approaches. Requirements Eng. 11, 58-78 (2006)

12. Brinkkemper, S.: Method engineering: engineering of information systems development methods and tools. Information and Software Technology 1995, 37 (1995)

13. Avison, D.E., Fitzgerald, G.: Information Systems Development: Methodologies, Techniques and Tools. McGraw Hill, Berkshire (1995)

14. Goldkuhl, G., Cronholm, S.: Customizable CASE environments: A Framework for Design and Evaluation. Accepted to COPE IT 1993/NordDATA, Copenhagen, June 14-16 (1993)

15. Goldkuhl, G., Lind, M., Seigerroth, U.: Method integration: the need for a learning perspective. IEE Proceedings, Software (special issue on Information System Methodologies) 145(4) (August 1998)

16. Lind, M., Seigerroth, U.: Team-based reconstruction for expanding organisational ability. Journal of the Operational Society 54, 119-129 (2003)

17. Stirna, J., Persson, A., Sandkuhl, K.: Participative enterprise modeling: Experiences and recommendations. In: Krogstie, J., Opdahl, A.L., Sindre, G. (eds.) CAiSE 2007 and WES 2007. LNCS, vol. 4495, pp. 546-560. Springer, Heidelberg (2007) 